\title{
EDITORIAL
}

Jackie Li • Dimitris Lagoudas • Abhijit Bhattacharyya

\section{Biography of the Prager Medalist: Professor George Weng}

Received: 21 October 2013 / Published online: 14 February 2014

(C) Springer-Verlag Wien 2014

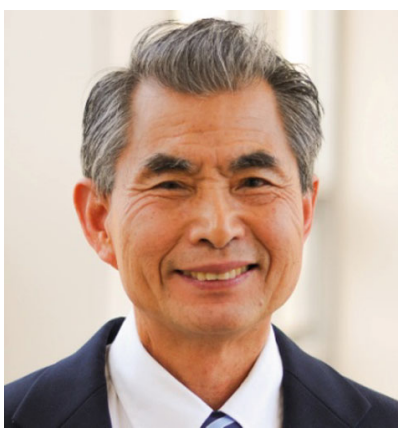

"For his outstanding research contributions in theoretical solid mechanics" by the Society of Engineering Science, 2013

Professor George Weng received his B.S. from National Taiwan University in Mechanical Engineering in 1967 and his Ph.D. from Yale in Engineering and Applied Science in 1974. Prior to receiving his degree, he spent one year at Delft University of Technology as a Research Fellow with Professor Peter Jongenburger from 1973 to 1974, another year as a Postdoc with Professor T. H. Lin of UCLA from 1975 to 1976. After one year of work at General Motors Research Laboratories, he joined Rutgers as an Assistant Professor in 1977. He was promoted to an Associate Professor in 1980, a Full Professor in 1984, and a Distinguished Professor (previously called Professor II) in 1992. The award of Prager Medal gave his former Ph.D. students, colleagues at Rutgers, and friends elsewhere much pleasure.

Weng started his professional life as a graduate student at Yale, working on the theory of yield surface based on dislocation mechanics under the supervision of Professor Aris Phillips. Phillips was a noted scientist

J. Li ( $\varangle)$

The City College of New York, New York, NY, USA

E-mail: j.li@ccny.cuny.edu

D. Lagoudas

Texas A\&M University, College Station, TX, USA

E-mail: d-lagoudas@tamu.edu

\author{
A. Bhattacharyya \\ The University of Arkansas at Little Rock, Little Rock, AR, USA \\ E-mail: axbhattachar@ualr.edu
}


in experimental plasticity. For many years, he had explored the nature of yield surface and hardening laws and reported many ground-breaking observations. His instruction to this young man was "we need some physical theories to explain all of these experiments". With it, he began to embark on a long journey of micromechanics study in solids.

Later, he used to tell his own graduate students that Phillips was a very liberal professor, that he gave him a world of freedom to do research and rarely checked his progress. This happened to suit him very well. He also said that occasionally, he would work at the circulation desk of the Engineering Library in the evening and read many books and articles that later turned out to be very useful. At that time, the theory of dislocations was an active area of research in materials science and yield surface was also a major focus in plasticity, but there was little or no connection between the two. Weng quickly recognized the importance of bringing the underlying dislocation behavior up to the continuum level, to provide the physical foundation for the properties of yield surfaces. The hardening rules of metals were dominated by Taylor's isotropic hardening, Prager's kinematic hardening, and Ziegler's modification, but no experimental data were reported to substantiate their validity. Phillips' experiments consistently demonstrated that, on top of the rigid body motion implied in kinematic hardening, the shape of the yield surface also tended to distort, with the front portion showing an inflated shape and the back a deflated one. Based on dislocation mechanics, he started to develop his own active and latent hardening laws for the slip systems of the constituent grains and then translated them up to the polycrystal level. In due course, he was able to provide the physical foundation for Phillips' extensive experiments. In 1974, he submitted his Ph.D. thesis entitled: The Investigation of Yield Surface by Dislocation Mechanics. From his thesis also grew several other papers on the physical origins of hardening laws in crystal plasticity. One of them was "Kinematic hardening rule in single crystals" published in 1979 that was akin to Prager's kinematic hardening rule, and another was "Anisotropic hardening in single crystals and the plasticity of polycrystals" in 1987, in memory of Aris Phillips.

This early work on the transition from dislocation theory to continuum plasticity quickly led to his study of single crystals versus polycrystals. From 1980, he began to present various self-consistent schemes for the single-to-polycrystal transition for the rate-independent and rate-dependent plasticity. These include the time-dependent creep, stress relaxation, unified plastic-creep deformation, and influence of fatigue stress, and he also developed a self-consistent model for dual-phase polycrystals, in which each phase was capable of undergoing crystallographic slips in its own constituent grains. This series of works spanned the period from 1980 to 1985.

The study on the self-consistent schemes of single crystals versus polycrystals in turn directed his attention to the broader issue of micromechanics of composites. He said in his early days he drew considerable inspirations from the writings of Eshelby, Hill, Kroner, Hashin and Shtrikman, Willis, Walpole, and Mura. His learning from Hill was more direct - he maintained a long stretch of communications with Hill for over two decades. Subsequently, the works of Christensen, Dvorak, and Nemat-Nasser also had a direct impact. The originality of their works proved to have far-reaching influence on his contributions to the theory of inclusions and elastic properties of reinforced solids. The study during this period also led to his discovery of the connection between Mori-Tanaka's theory and the Hashin-Shtrikman-Walpole bounds. Some of the papers he wrote along this line are now widely known. In particular, the two papers he wrote in 1984 and 1990 have proved to have some fundamental importance to the foundation of the Mori-Tanaka method, and another two, jointly written with his Ph.D. student G.P. Tandon in 1984 and 1986, are known to have some particular value for applications.

Based on his study of elastic properties, he then moved on to the plasticity of particle-reinforced composites. In order to study this nonlinear problem, he introduced the concept of secant moduli into the elastic framework in 1988. The usefulness of the secant moduli also became evident in the study of dual-phase metals, and in the formulation of plastic potential and yield function of porous materials and composites that he subsequently carried out with his Ph.D. student Y.P. Qiu. In the meantime, he also started to work on the properties of viscoelastic composites with his other Ph.D. student, Y.M. Wang. The concept of secant moduli for rate-independent plasticity was soon extended into secant viscosity for the rate-dependent viscoplasticity and creep with his Ph.D. student J. Li. Both the secant moduli and the secant viscosity approaches have also proven to have wide applicability for the study of rate-independent and rate-dependent plastic behavior of particle-reinforced solids.

While the volume concentration of particles or inclusions tends to remain constant in ordinary composites, it will evolve during phase transitions. The issue of volume change was initially taken up with his Ph.D. student H. H. Pan around 1992, to study transformation toughening. Subsequently, in 1994, he and his other Ph.D. student A. Bhattacharyya, started to investigate the problem of phase transition in a ductile system, with an eye on the behavior of TRIP (transformation-induced plasticity) steels. They developed an energy criterion based on Gibbs free energy to calculate the evolution of martensite plates from the ductile austenite matrix 
during the martensitic transformation. With it, they were able to demonstrate how the total nonlinear strain was attributed to two different sources, one from the traditional plastic strain and the other from the phase transformation strain. The overall stress-strain curve then exhibits the widely observed sigmoidal shape, a common phenomenon that had never been explained from the micromechanics perspective.

Around this time, the study of shape memory alloys (SMAs) was very active in the US, and challenge to the understanding of multifunctional materials also began to emerge. In 1997, he began to extend the nonlinear theory he developed for TRIP steels to study the phase transition in SMAs with his Ph.D. student Z. K. Lu. Based on the developed Gibbs free energy for a dual-phase system, the concepts of thermodynamic driving force and kinetic equations were soon developed and applied to explain and predict the pseudoelastic behavior and shape memory effects of SMA single crystals, polycrystals, and SMA-reinforced composites. Though his number of publications in SMAs was not high, his 1997 and 1998 papers are known to provide a solid foundation for the study of inclusion-based phase transition in thermoelastic systems.

In 1999, he and J. Li began to extend the principle of phase transition in SMAs to ferroelectric crystals. With the introduction of electromechanical coupling, spontaneous strain, and spontaneous polarization, they formulated a micromechanics-based thermodynamics theory for the domain switch. Soon after and jointly with his Ph.D. student, Y. Su, he began to extend the framework of domain switch to phase transition in ferroelectric crystals and brought it from the grain level to the level of polycrystalline aggregates. In this series of works, the issues of shift of Curie temperature, influence of pressure and electric field, formation of double and triple hysteresis, and change of dielectric constant during phase transition, had all been accounted for. His contributions have indeed added a new dimension to our knowledge of ferroelectric phenomena.

With the emergence of nanocrystalline materials, he began to develop the micromechanics theory with his Postdoc, Bing Jiang, for this class of new materials around 2003 and used it to study the grain-size dependence-or the Hall-Petch and the inverse Hall-Petch relations-of their yield strength. The objective was to find the optimal grain size at which the material could have the maximum yield strength. The study hinged upon the delicate competition of grain-size hardening and grain-boundary softening with the decrease in grain size. His works represented a drastic departure from the then widely adopted rule of mixture approach in the materials community. The focus of rate-independent plasticity in his early papers was soon extended to the rate-dependent viscoplasticity and creep to study the grain-size dependence, strain-rate sensitivity, and activation volume with $\mathrm{J}$. Li and graduate student P. Barai. His study on nanocrystalline materials spanned the period of 2003-2010. Both his rate-independent and rate-dependent studies have brought significant new physical insights into the competition of grain interiors, GB zone, and grain-boundary sliding.

At the same time, he also became very interested in the mechanical and transport properties of carbon nanotube-based composites. Carbon nanotubes are known to have exceptional elastic stiffness, and extremely high thermal and electrical conductivities, but various experiments on CNT-based composites continued to show that the measured effective properties could not reach the expected levels of effective properties. His work with P. Barai in 2011 on the plasticity of carbon nanotube-reinforced composite pointed out that, while CNTS are in general a very effective strengthening agent, both CNT agglomerations and the imperfect interface condition have proven to be two key detrimental factors that limited the potential of their plastic strength. His other work on CNT-based thermal conductivity with Prof. T. Chen in 2005 pointed out that the Kapitza interfacial contact and the poor tube-end transport were the two main sources that limit the attainment of the theoretical values. Over the past two years, he and Prof. S. Meguid have jointly studied the effective electrical conductivity of CNT-based polymer composites by looking into the issues of percolation threshold and electron tunneling resistance between CNT junctions. Some exciting results have been obtained and reported in the literature.

At present, his focus is on the micromechanics and phase fields of multiferroic composites for strong magnetoelectric coupling. He continues to pursue the issues of percolation theory and network formation for the transport properties of CNT- and graphene-based polymer composites.

Over the past two decades, Weng was fortunate enough to have several very able visiting scientists to come to Rutgers. These include Prof. Y. H. Zhao from Dalian, Prof. T. Sakaki from Tokyo, Prof. Cewen Nan from Tsinghua, Prof. Wenfang Li from SCUT, and Prof. Chunyu Li from Shijiazhuang. Many of them are now very well-established scientists. He also had the fortune to work with Prof. Gengkai Hu of BIT and Prof. Keichiro Tohgo of Shizuoka. These and many of his other Ph.D. students have all greatly contributed to his research activities.

In addition to his scholarly outputs, Weng has also contributed to the field of solid mechanics in several other ways. He has been an Editor of Acta Mechanica since 1985 and was the Technical Editor of ASME Journal of Engineering Materials and Technology from 1992 to 1997. At present, he also serves on the Edi- 
torial or Advisory Boards of Mechanics of Materials, International Journal of Mechanics and Materials in Design, Journal of Mechanical Behavior of Materials, and Acta Mechanica Solida Sinica. Previously, he was on the Boards of International Journal of Plasticity, JSME International Journal Series A: Solid Mechanics and Materials Engineering, and Mechanics of Advanced Materials and Structures, among others. He was Chairman of the ASME Materials Division Executive Committee from 1993 to 1994 and Chairman of the ASME Materials Division 75th Anniversary Diamond Jubilee Lectures in San Francisco in 1995. He has given several opening and plenary lectures and many keynote lectures at national and international conferences, and has edited several special volumes and books. Weng is also a Fellow of the American Society of Mechanical Engineers, a Fellow of the American Academy of Mechanics, and a Life Member of the Society of Engineering Science.

His Prager Medal citation appropriately reads: "in recognition of his fundamental contributions to the theory of inclusions, micromechanics of composites, multifunctional materials, and coupled behavior in solids". Over the past three decades, his research interests have continued to evolve and are still evolving. We fully expect that his continued pursuit of engineering science will bring to us yet another level of understanding to solid mechanics.

\section{Journal publications by G. J. Weng (1974-2013)}

1. P. Jongenburger, A. Wachters and G.J. Weng. Plastic anisotropy of textured steel sheets. Metall. Trans. 5, 2451-2455 (1974).

2. A. Phillips and G.J. Weng. An analytical study of an experimentally verified hardening law. J. Appl. Mech. 42, 375-378 (1975).

3. G.J. Weng and A. Phillips. On the kinematics of continuous distribution of dislocations in plasticity. Int. J. Engng. Sci. 14, 65-73 (1976).

4. G.J. Weng and A. Phillips. An investigation of yield surface based on dislocation mechanics. I. Basic theory. Int. J. Engng. Sci. 15, 45-59 (1977).

5. G.J. Weng and A. Phillips. An investigation of yield surface based on dislocation mechanics. II. Applications. Int. J. Engng. Sci. 15, 61-70 (1977).

6. T.H. Lin, C.L. Yu and G.J. Weng. Derivation of polycrystal creep properties from the creep data of single crystals. J. Appl. Mech. 44, 73-78 (1977).

7. G.J. Weng and A. Phillips. The stress field of continuous distribution of dislocations and of their movement in a polycrystalline aggregate. Int. J. Solids Struct. 14, 535-544 (1978).

8. G.J. Weng. Parametric response of a metallic column at elevated temperature. Int. J. Non-Linear Mech. 14, 123-132 (1979).

9. D.C. Chang and G.J. Weng. Elastic moduli of randomly oriented, chopped fiber composites with filled resin. J. Mater. Sci. 14, 2183-2190 (1979).

10. G.J. Weng. Kinematic hardening rule in single crystals. Int. J. Solids Struct. 15, 861-870 (1979).

11. G.J. Weng. A physically consistent method for the prediction of creep behavior of metals. J. Appl. Mech. 46, 800-804 (1979).

12. Z.H. Kalman, J. Chaudhuri, G.J. Weng and S. Weissmann. Determination of strain concentration by microfluorescent densitometry of X-ray topography: A bridge between microfracture and continuum mechanics. J. Appl. Crystall. 13, 290-296 (1980).

13. C.T. Chon and G.J. Weng. Impact of a finite elastic-viscoplastic bar. Int. J. Non-Linear Mech. 15, 195-209 (1980).

14. G.J. Weng. Constitutive equations of single crystals and polycrystalline aggregates under cyclic loading. Int. J. Engng. Sci. 18, 1385-1397 (1980).

15. G.J. Weng. Dislocation theory of work hardening and yield surface of single crystals. Acta Mech. 37, 217-230, (1980).

16. G.J. Weng. The yield surface of single crystals at arbitrary strain. Acta Mech. 37, 231-245 (1980).

17. G.J. Weng. Constitutive relations of metal crystals at arbitrary strain. Acta Mech. 41, 217-232 (1981).

18. G.J. Weng. Self-consistent determination of time-dependent behavior of metals. J. Appl. Mech. 48, 41-46 (1981).

19. G.J. Weng. A self-consistent scheme for the relaxation behavior of metals. J. Appl. Mech. 48, 779-784 (1981). 
20. J. Chaudhuri, Z.H. Kalman, G.J. Weng and S. Weissmann. Determination of the strain concentration factor around holes and inclusions in crystals by X-ray topography. J. Appl. Crystall. 15, 423-429 (1982).

21. H.Y. Liu, G.J. Weng and S. Weissmann. Determination of notch tip plasticity by X-ray diffraction and comparison to continuum mechanics analysis. J. Appl. Crystall. 15, 594-601 (1982).

22. G.J. Weng. A unified, self-consistent theory for the plastic-creep deformation of metals. J. Appl. Mech. 49, 728-734 (1982).

23. G.J. Weng. Cyclic stress relaxation of polycrystalline metals at elevated temperature. Int. J. Solids Struct. 19, 541-551 (1983).

24. G.J. Weng. The influence of fatigue stress on the creep behavior of metals. Acta Metall. 31, 207-212 (1983).

25. G.J. Weng. A micromechanical theory of grain-size dependence in metal plasticity. J. Mech. Phys. Solids 31, 193-203 (1983).

26. G.J. Weng. Tensile creep acceleration by superimposed cyclic torsional strain in polycrystalline metals. Mater. Sci. Engng. 57, 127-133 (1983).

27. C.R. Chiang and G.J. Weng. Transition of plastic behavior from single crystal to polycrystal under pure tension, and the effect of multislip. J. Engng. Mater. Tech. 106, 311-316 (1984).

28. G.J. Weng and C.R. Chiang. Self-consistent relation in polycrystalline plasticity with a non-uniform matrix. Int. J. Solids Struct. 20, 689-698 (1984).

29. G.J. Weng. Some elastic properties of reinforced solids, with special reference to isotropic ones containing spherical inclusions. Int. J. Engng. Sci. 22, 845-856 (1984).

30. G.P. Tandon and G.J. Weng. The effect of aspect ratio of inclusions on the elastic properties of unidirectionally aligned composites. Polymer Composites 5, 327-333 (1984).

31. G.J. Weng. The effect of temperature and solute content on the plastic properties of polycrystalline alloys. Mater. Sci. Engng. 62, 57-63 (1984).

32. G.J. Weng. Micromechanical determination of two-phase plasticity. Int. J. Plasticity 1, 275-287 (1985).

33. G.P. Tandon and G.J. Weng. Average stress in the matrix and effective moduli of randomly oriented composites, Composite Sci. Tech. 27, 111-132 (1986).

34. G.P. Tandon and G.J. Weng. Stress distribution in and around spheroidal inclusions and voids at finite concentration. J. Appl. Mech. 53, 511-518 (1986).

35. G.J. Weng. Anisotropic hardening in single crystals and the plasticity of polycrystals. Int. J. Plasticity (in memory of Aris Phillips) 3, 315-339 (1987).

36. Z.G. Zhu and G.J. Weng. Theoretical calculation of creep and relaxation of polycrystals, and stress redistribution among constituent grains. J. Mater. Sci. 22, 1390-1396 (1987).

37. G.J. Weng. A micromechanical theory of high temperature creep. J. Appl. Mech. 54, 822-827 (1987).

38. H.A. Luo and G.J. Weng. On Eshelby's inclusion problem in a three-phase spherically concentric solid, and a modification of Mori-Tanaka's method. Mech. Mater. 6, 347-361 (1987).

39. Z.G. Zhu and G.J. Weng. Micromechanics of time-dependent deformation in a dispersion-hardened polycrystal. Acta Mech. 69, 295-313 (1987).

40. G.P. Tandon and G.J. Weng. A theory of particle-reinforced plasticity. J. Appl. Mech. 55, 126-135 (1988).

41. Z.G. Zhu and G.J. Weng. Creep deformation of particle-strengthened metal-matrix composites. $J$. Engng. Mater. Tech. 111, 99-105 (1989).

42. Y.H. Zhao, G.P. Tandon and G.J. Weng. Elastic moduli for a class of porous materials. Acta Mech. 76, 105-130 (1989).

43. H.A. Luo and G.J. Weng. On Eshelby's S-tensor in a three-phase cylindrically concentric solid, and the elastic moduli of fiber-reinforced composites. Mech. Mater. 8, 77-88 (1989).

44. G.J. Weng. The theoretical connection between Mori-Tanaka's theory and the Hashin-Shtrikman-Walpole bounds. Int. J. Engng. Sci. 28, 1111-1120 (1990).

45. Y.P. Qiu and G.J. Weng. On the application of Mori-Tanaka's theory involving transversely isotropic inclusions. Int. J. Engng. Sci. 28, 1121-1137 (1990).

46. G.J. Weng. The overall elastoplastic stress-strain relations of dual-phase metals. J. Mech. Phys. Solids 38, 419-441 (1990).

47. Z.G. Zhu and G.J. Weng. A local theory for the calculation of overall creep strain of particle-reinforced composites. Int. J. Plasticity 6, 449-469 (1990). 
48. Y.H. Zhao and G.J. Weng. Effective elastic moduli of ribbon reinforced composites. J. Appl. Mech. 57, 158-167 (1990).

49. Z.G. Zhu and G.J. Weng. Creep anisotropy of a metal-matrix composite containing dilute concentration of aligned spheroidal inclusions. Mech. Mater. 9, 93-105 (1990).

50. Y.P. Qiu and G.J. Weng. The influence of inclusion shape on the overall elastoplastic behavior of a two-phase isotropic composite. Int. J. Solids Struct. 27, 1537-1550 (1991).

51. Y.P. Qiu and G.J. Weng. Elastic moduli of thickly coated particle and fiber-reinforced composites. $J$. Appl. Mech. 58, 388-398 (1991).

52. Y.P. Qiu and G.J. Weng. Elastic constants of a polycrystal with transversely isotropic grains, and the influence of precipitates. Mech. Mater. 12, 1-15 (1991).

53. H.H. Pan and G.J. Weng. Thermal stress and volume change during a cooling process involving phase transformation. J. Thermal Stress (The Bruno A. Boley $65^{\text {th }}$ anniversary volume) 13, 1-23 (1992).

54. G.J. Weng. Explicit evaluation of Willis' bounds with ellipsoidal inclusions. Int. J. Engng. Sci. 30, 83-92 (1992).

55. Y.M. Wang, Y.P. Qiu and G.J. Weng. Transient creep behavior of a metal-matrix composite with dilute concentration of randomly oriented spheroidal inclusions. Composite Sci. Tech. 44, 287-297 (1992).

56. Y.P. Qiu and G.J. Weng. A theory of plasticity for porous materials and particle-reinforced composites. J. Appl. Mech. 59, 261-268 (1992).

57. Y.M. Wang and G.J. Weng. Transient creep strain of a metal-matrix composite under transverse loading. J. Engng. Mater. Tech. 114, 237-244 (1992).

58. A. Farouk, N. Langrana and G.J. Weng. Modulus prediction of a cross-ply fiber reinforced fabric composite with voids. Polymer Composites 13, 285-295 (1992).

59. Y.M. Wang and G.J. Weng. The influence of inclusion shape on the overall viscoelastic behavior of composites. J. Appl. Mech. 59, 510-518 (1992).

60. H.H. Pan and G.J. Weng. Determination of transient and steady-state creep of metal-matrix composites by a secant-moduli method. Composites Engng. 3, 661-674 (1993).

61. H.H. Pan and G.J. Weng. Thermal stress relief by plastic deformation in aligned two-phase composites. Composites Engng. 3, 219-234 (1993).

62. G.J. Weng. A self-consistent relation for the time-dependent creep of polycrystals. Int. J. Plasticity 9, 181-198 (1993).

63. Y.P. Qiu and G.J. Weng. Plastic potential and yield function of porous materials with aligned and randomly oriented spheroidal voids. Int. J. Plasticity 9, 271-290 (1993).

64. A. Bhattacharyya, T. Sakaki and G.J. Weng. The influence of martensite shape, concentration and phase transformation strain on the deformation behavior of stable dual-phase steels. Metall. Trans. 24A, 301-314 (1993).

65. Y.M. Wang and G.J. Weng. Self-similar and transient void growth in viscoelastic media at low concentration. Int. J. Fracture 61, 1-16 (1993).

66. K.M. Murali and G.J. Weng. Theoretical calculation of anisotropic creep and stress-strain behavior for a class of metal-matrix composites. Metall. Trans. 24A, 2049-2059 (1993).

67. K.M. Murali and G.J. Weng. A unified determination of creep and strain-rate sensitivity of polycrystals from the properties of constituent grains. Mater. Sci. Engng. A172, 43-49 (1993).

68. K.M. Murali and G.J. Weng. The influence of particle concentration on the high-temperature stressstrain behavior of metal-matrix composites. J. Mech. Behavior Mater. 4, 353-363 (1993).

69. A. Bhattacharyya and G.J. Weng. Plasticity of isotropic composites with randomly oriented and packeted inclusions. Int. J. Plasticity 10, 553-578 (1994).

70. J. Li and G.J. Weng. Anisotropic stress-strain relations and complex moduli of a viscoelastic composite with aligned inclusions. Composites Engng. 4, 1073-1097 (1994).

71. J. Li and G.J. Weng. Effective creep behavior and complex moduli of fiber and ribbon- reinforced polymer-matrix composites. Composite Sci. Tech. 52, 615-629 (1994).

72. A. Bhattacharyya and G.J. Weng. Pressure sensitivity and strength-differential effect of fiber-reinforced polymer matrix composites. Mech. Mater. 17, 329-349 (1994).

73. K. Tohgo and G.J. Weng. A progressive damage mechanics in particle-reinforced metal-matrix composites under high triaxial tension. J. Engng. Mater. Tech. 116, 414-420 (1994).

74. J. Li and G.J. Weng. Strain-rate sensitivity, relaxation behavior and complex moduli of a class of isotropic viscoelastic composites. J. Engng. Mater. Tech. 116, 495-504 (1994). 
75. A. Bhattacharyya and G.J. Weng. An energy criterion for the stress-induced martensitic transformation in a ductile system. J. Mech. Phys. Solids 42, 1699-1724 (1994).

76. A. Bhattacharyya and G.J. Weng. The elastoplastic behavior of a class of two-phase composites containing rigid inclusions. Appl. Mech. Reviews 47, S45-65 (1994).

77. H.H. Pan and G.J. Weng. Elastic moduli of heterogeneous solids with ellipsoidal inclusions and elliptic cracks. Acta Mech. 110, 73-94 (1995).

78. Y.P. Qiu and G.J. Weng. An energy approach to the plasticity of a two-phase composite containing aligned inclusions. J. Appl. Mech. 62, 1039-1046 (1995).

79. Y.H. Zhao and G.J. Weng. A theory of inclusion debonding and its influence on the stress-strain relations of a ductile matrix composite. Int. J. Damage Mech. (in memory of Lazar M. Kachanov) 4, 196-211 (1995).

80. Y.H. Zhao and G.J. Weng. Influence of random bridging on the elastic and elastoplastic properties of fiber-reinforced composites. Acta Mech. 116, 29-44 (1996).

81. Z.K. Lu and G.J. Weng. A simple unified theory for the cyclic deformation of metals at high temperature. Acta Mech. 118, 135-149 (1996).

82. Y.H. Zhao and G.J. Weng. Plasticity of a two-phase composite with partially debonded inclusions. Int. J. Plasticity 12, 781-804 (1996).

83. J. Li and G.J. Weng. Effect of a viscoelastic interphase on the creep and stress-strain behavior of fiber-reinforced polymer matrix composites. Composites Engng. 27, 589-598 (1996).

84. J. Li and G.J. Weng. Orthotropic creep and complex moduli of a viscoelastic composite reinforced with aligned elliptic cylinders. J. Composite Mater. 30, 1042-1066 (1996).

85. T. Sakaki, G.J. Weng, K. Kakehi and S. Hashimoto. Plastic anisotropy of sheets with continuously varying anisotropic parameters and flow stress. Metall. Mater. Trans. 27A, 317-326 (1996).

86. J. Li and G.J. Weng. Void growth and stress-strain relations of a class of viscoelastic porous materials. Mech. Mater. 22, 179-188 (1996).

87. J.M. Baney, Y.H. Zhao and G.J. Weng. Progressive debonding of aligned oblate inclusions and loss of stiffness in a brittle matrix composite. Engng. Fracture Mech. 53, 897-901 (1996).

88. S. Govindarajan, N.A. Langrana and G.J. Weng. An experimental and theoretical investigation of creep behavior of a graphite/epoxy woven composite. Polymer Composites 17, 353-361 (1996).

89. A. Bhattacharyya and G.J. Weng. Theoretical calculation of the stress-strain behavior of dual-phase metals with randomly oriented spheroidal inclusions. Metall. Mater. Trans. 27A, 2359-2365 (1996).

90. Z.K. Lu and G.J. Weng. Multiaxial constitutive modeling of aircraft engine materials. Finite Elements in Analysis and Design 23, 319-332 (1996).

91. S. Govindarajan, N.A. Langrana and G.J. Weng. The influence of imperfections on the creep behavior of woven polymer composites at elevated temperatures. Finite Elements in Analysis and Design 23, 333-347 (1996).

92. J. Li and G.J. Weng. Stress-strain relations of a viscoelastic composite reinforced with elliptic cylinders. J. Thermoplastic Composite Mater. 10, 19-30 (1997).

93. J. Li and G.J. Weng. A homogenization theory for the overall creep of isotropic viscoplastic composites. Acta Mech. (The Franz Ziegler $60^{\text {th }}$ anniversary volume) $125,141-153$ (1997).

94. Y.H. Zhao and G.J. Weng. Transversely isotropic moduli of two partially debonded composites. Int. J. Solids Struct. 34, 493-507 (1997).

95. J. Li and G.J. Weng. A secant-viscosity approach to the time-dependent creep of an elastic-viscoplastic composite. J. Mech. Phys. Solids 45, 1069-1083 (1997).

96. J. Li and G.J. Weng. Influence of inclusion microgeometry on some thermomechanical properties of isotropic polymer-matrix composites. J. Engng. Mater. Tech. 119, 242-250 (1997).

97. Z.K. Lu and G.J. Weng. Martensitic transformation and stress-strain relations of shape-memory alloys. J. Mech. Phys. Solids 45, 1905-1928 (1997).

98. J. Li and G.J. Weng. A unified approach from elasticity to viscoelasticity to viscoplasticity of particle-reinforced solids. Int. J. Plasticity (in memory of James F. Bell), 14, 193-208 (1998).

99. J. Li and G.J. Weng. Time-dependent creep of a dual-phase viscoplastic material with lamellar structure. Int. J. Plasticity 14, 755-770 (1998).

100. K. Ding and G.J. Weng. The influence of moduli slope of a linearly graded matrix on the bulk moduli of some particle- and fiber-reinforced composites. J. Elasticity 53, 1-22 (1999).

101. J. Li and G.J. Weng. Creep of a composite with dual viscoplastic phases. Compos. Sci. Tech. 58, 1803-1810 (1998). 
102. G.K. Hu and G.J. Weng. Influence of thermal residual stresses on the composite macroscopic behavior. Mech. Mater. 27, 229-240 (1998).

103. K. Ding and G.J. Weng. Plasticity of particle-reinforced composites with a ductile interphase. J. Appl. Mech. 65, 596-604 (1998).

104. Z.K. Lu and G.J. Weng. A self-consistent model for the stress-strain behavior of shape-memory alloy polycrystals. Acta Mater. 46, 5423-5433 (1998).

105. K. Ding and G.J. Weng. The influence of a ductile interphase on the overall elastoplastic behavior of a unidirectional fiber-reinforced composite. J. Appl. Mech. 66, 21-31 (1999).

106. C.W. Nan and G.J. Weng. Influence of microstructural features on the effective magnetostriction of composite materials. Phys. Rev. B 60, 6723-6730 (1999).

107. J. Li and G.J. Weng. A theory of domain switch for the nonlinear behavior of ferroelectrics. Proc. R. Soc. London A455, 3493-3511 (1999).

108. G.K. Hu and G.J. Weng. Some reflections on the Mori-Tanaka and Ponte Castaneda-Willis methods with randomly oriented ellipsoidal inclusions. Acta Mech. 140, 31-40 (2000).

109. Z.K. Lu and G.J. Weng. A two-level micromechanical theory for a shape-memory alloy reinforced composite. Int. J. Plasticity 16, 1289-1307 (2000).

110. S.F. Zheng, K. Ding, M. Denda and G.J. Weng. A dual homogenization and finite-element study on the in-plane local and global behavior of a nonlinear coated fiber composite. Computer Meth. Appl. Mech. Engng. 183, 141-155 (2000).

111. C.W. Nan and G.J. Weng. Theoretical approach to effective electrostriction in inhomogeneous materials. Phys. Rev. B 61, 258-265 (2000).

112. C.W. Nan and G.J. Weng. Electrostrictive coefficients of polycrystalline ceramics. J. Mater. Sci. Lett. 19, 291-293 (2000).

113. C.W. Nan and G.J. Weng. The bounds of electrostrictive coefficients of relaxor based ferroelectric ceramics. Phil. Mag. Lett. 80, 445-451 (2000).

114. C.W. Nan, Y. Huang and G.J. Weng. Effect of porosity on the effective magnetostriction of polycrystals. J. Appl. Phys. 88, 339-343 (2000).

115. C.W. Nan and G.J. Weng. Influence of polarization orientation on the effective properties of piezoelectric composites. J. Appl. Phys. 88, 416-423 (2000).

116. G.K. Hu and G.J. Weng. The connections between the double-inclusion model and the Ponte Castaneda-Willis, Mori-Tanaka, and Kuster-Toksoz models. Mech. Mater. 32, 495-503 (2000).

117. Z.K. Lu and G.J. Weng. A micromechanical theory for the thermally induced martensitic transformation in shape memory alloys. Smart Mater. Struct. 9, 582-591 (2000).

118. Y.M. Jin and G.J. Weng. Micromechanics study of thermomechanical characteristics of polycrystal shape-memory alloy films. Thin Solid Films 376, 198-207 (2000).

119. S.F. Zheng, M. Denda and G.J. Weng. Interfacial partial debonding and its influence on the elasticity of a two-phase composite. Mech. Mater. 32, 695-709 (2000).

120. C.Y. Li, G.J. Weng, Z.P. Dunn and Z. Zou. Dynamic stress intensity factor of a functionally graded material under antiplane shear loading. Acta Mech. 149, 1-10 (2001).

121. J. Li and G.J. Weng. A micromechanics-based hysteresis model for ferroelectric ceramics. J. Intell. Mater. Systems Struct. 12, 79-91 (2001).

122. Y.M. Jin and G.J. Weng. A relaxed constraint model for the tensile behavior of polycrystal shapememory alloy wires. Metall. Mater. Trans. 32A, 305-313 (2001).

123. C.Y. Li and G.J. Weng. Dynamic stress intensity factor of a cylindrical interface crack with a functionally graded interlayer. Mech. Mater. 33, 325-333 (2001).

124. G.K. Hu and G.J. Weng. A new derivative on the shift property of effective elastic compliances for planar and 3-D composites. Proc. R. Soc. London A457, 1675-1684 (2001).

125. C.W. Nan, J.H. Huang and G.J. Weng. Effective magnetostriction of nanocrystalline magnetic materials: the interface effect. J. Magn. Magn. Mater. 233, 219-223 (2001).

126. W.F. Li and G.J. Weng. Micromechanics simulation of spontaneous polarization in ferroelectric crystals. J. Appl. Phys. 90, 2484-2491 (2001).

127. C.Y. Li, G.J. Weng and Z.P. Dunn. Dynamic behavior of a cylindrical crack in a functionally graded interlayer under torsional loading. Int. J. Solid Struct. 38, 7473-7485 (2001).

128. C.R. Chiang and G.J. Weng. A new look at Hill's arithmetic and geometric means for a two-phase, isotropic composite. Acta Mech. 156, 1-12 (2002). 
129. H.H. Pan and G.J. Weng. A micromechanics theory for the transformation toughening of two-phase ceramics. Acta Mech. 156, 47-62 (2002).

130. C.Y. Li and G.J. Weng. Yoffe-type moving crack in a functionally graded piezoelectric material. Proc. R. Soc. London A458, 381-399 (2002).

131. W.F. Li and G.J. Weng. A theory of ferroelectric hysteresis with a superimposed stress. J. Appl. Phys. 91, 3806-3815 (2002).

132. C.Y. Li and G.J. Weng. Dynamic fracture analysis for a penny-shaped crack in an FGM interlayer between dissimilar half spaces. Math. Mech. Solids 7, 149-163 (2002).

133. S.F. Zheng and G.J. Weng. A new constitutive equation for the long-term creep of polymers based on physical aging. Euro. J. Mech. A/Solids 21, 411-421 (2002).

134. Y.H. Zhao and G.J. Weng. The effect of debonding angle on the reduction of effective moduli of particle and fiber-reinforced composites, J. Appl. Mech. 69, 292-302 (2002).

135. Y.M. Jin and G.J. Weng. A direct method for the crystallography of martensitic transformation and its application to TiNi and AuCd. Acta Mater. 50, 2967-2987 (2002).

136. C.Y. Li and G.J. Weng. Anti-plane crack problem in functionally graded piezoelectric materials. $J$. Appl. Mech. 69, 481-488 (2002).

137. S.F. Zheng, M. Denda and G.J. Weng. Overall elastic and elastoplastic behavior of a partially debonded fiber-reinforced composite. J. Composite Mater. 37, 741-758 (2003).

138. H.H. Pan and G.J. Weng. Transformation toughening of a two-phase, transversely isotropic solid. Chinese J. Mech. (The Thomas C.T. Ting 70th anniversary volume) A19, 133-141 (2003).

139. B. Jiang and G.J. Weng. A composite model for the grain-size dependence of yield stress of nanograined materials. Metall. Mater. Trans. 34A, 765-772 (2003).

140. T. Chen, C.-W. Nan and G.J. Weng. Exact connections between effective magnetostriction and effective elastic moduli of fibrous composites and polycrystals. J. Appl. Phys. 94, 491-495 (2003).

141. G.J. Weng. Effective bulk moduli of two functionally graded composites. Acta Mech. 166, 57-67 (2003).

142. T. Chen, C.-W. Nan, G.J. Weng and G.-X. Chen. Unified approach for the estimate of effective magnetostriction of composites and polycrystals with particulate and columnar microstructures. Phys. Rev. B 68, 224406 1-9, (2003).

143. B. Jiang and G.J. Weng. A theory of compressive yield strength of nano-grained ceramics. Int. J. Plasticity (in memory of Daniel C. Drucker) 20, 2007-2026 (2004).

144. B. Jiang and G.J. Weng. A generalized self-consistent polycrystal model for the yield strength of nanocrystalline materials. J. Mech. Phys. Solids 52, 1125-1149 (2004).

145. W.F. Li and G.J. Weng. A micromechanics-based thermodynamic model for the domain switch in ferroelectric crystals. Acta Mater. 52, 2489-2496 (2004).

146. W.F. Li and G.J. Weng. Effects of microstructures, porosity, and external pressure on the phase transition of ferroelectric ceramics. Int. J. Mech. Mater. in Design 1, 17-32 (2004).

147. T. Chen, G.J. Weng and W.C. Liu. Effect of Kapitza contact and consideration of tube-end transport on the effective conductivity in nano-tube based composites. J. Appl. Phys. 97, 104312 (2005).

148. C.R. Chiang and G.J. Weng. The nature of stress and electric-displacement concentrations around a strongly oblate cavity. Int. J. Fracture 134, 319-337 (2005).

149. Y. Su and G.J. Weng. The shift of Curie temperature and evolution of ferroelectric domain in ferroelectric crystals. J. Mech. Phys. Solids 53, 2071-2099 (2005).

150. Z.M. Xiao, J.Y. Guo and G.J. Weng. A piezoelectric inhomogeneity interacting with a branched crack. Int. J. Computational Methods 4, 1-20 (2006).

151. N. Srivastava and G.J. Weng. A theory of double hysteresis for ferroelectric crystals. J. Appl. Phys. 99, 054103 1-11 (2006).

152. Y. Su and G.J. Weng. A polycrystal hysteresis model for ferroelectric ceramics. Proc. R. Soc. London A462, 1573-1592 (2006).

153. Y. Su and G.J. Weng. A self-consistent polycrystal model for the spontaneous polarization of ferroelectric ceramics. Proc. R. Soc. London A462, 1763-1789 (2006).

154. N. Srivastava and G.J. Weng. A dual-phase homogenization theory for the hysteresis and butterflyshaped behavior of ferroelectric single crystals. Mech. Mater. 38, 945-957 (2006).

155. Y. Su and G.J. Weng. A polycrystal model for the anisotropic behavior of a fully poled ferroelectric ceramic. J. Appl. Phys. 100, 114110 1-8 (2006). 
156. N. Srivastava and G. J. Weng. The influence of a compressive stress on the nonlinear response of ferroelectric crystals. Int. J. Plasticity 23, 1860-1873 (2007).

157. J. Li and G. J. Weng. A secant-viscosity composite model for the strain-rate sensitivity of nanocrystalline materials. Int. J. Plasticity 23, 2115-2133 (2007).

158. C.R. Chiang and G.J. Weng. Nonlinear behavior and critical state of a penny-shaped dielectric crack in a piezoelectric solid. J. Appl. Mech. 74, 852-860 (2007).

159. P. Barai and G.J. Weng. Mechanics of creep resistance in nanocrystalline solids. Acta Mech. (The Franz Ziegler $70^{\text {th }}$ anniversary volume) $195,327-348$ (2008).

160. P. Barai and G.J. Weng. The competition of grain size and porosity in the viscoplastic response of nanocrystalline solids. Int. J. Plasticity 24, 1380-1410 (2008).

161. T.H. Kuo, H.H. Pan and G.J. Weng. Micromechanics-based predictions on the overall stress-strain relations of cement-matrix composites. ASCE J. Engng. Mech. 134, 1045-1052 (2008).

162. R. Hashemi, R. Avazmohammadi, H.M. Shodja and G.J. Weng. Composites with superspherical inhomogeneities. Phil. Mag. Lett. 89, 439-451 (2009).

163. G.J. Weng. A homogenization scheme for the plastic properties of nanocrystalline materials. Rev. Adv. Mater. Sci. 19, 41-62 (2009).

164. G.J. Weng and D.T. Wong. Thermodynamic driving force in ferroelectric crystals with a rank-2 laminated domain pattern, and a study of enhanced electrostriction. J. Mech. Phys. Solids 57, 571-597 (2009).

165. R. Avazmohammadi, R. Naghdabadi and G.J. Weng. Finite anti-plane shear deformation of nonlinear elastic composites reinforced with elliptic fibers. Mech. Mater. 41, 868-877 (2009).

166. G.J. Weng. A theory of triple hysteresis in ferroelectric crystals. J. Appl. Phys. 106, 074109 (2009).

167. Y. Su and G.J. Weng. Microstructural evolution and overall response of an initially isotropic ferroelectric polycrystal under an applied electric field. Mech. Mater. (The Leon Keer $75^{\text {th }}$ anniversary volume) 41, 1179-1191 (2009).

168. P. Barai and G.J. Weng. Mechanics of very fine-grained nanocrystalline materials with contributions from the grain interior, GB zone, and grain-boundary sliding. Int. J. Plasticity 25, 2410-2434 (2009).

169. H.H. Pan and G.J. Weng. Study on the strain-rate sensitivity of cementitious composites. ASCE $J$. Engng. Mech. 136, 1076-1082 (2010).

170. G.J. Weng. A dynamical theory for the Mori-Tanaka and Ponte Castaneda-Willis estimates. Mech. Mater. 42, 886-893 (2010).

171. R. Hashemi, G.J. Weng, M.H. Kargarnovin and H.M. Shodja. Piezoelectric composites with periodic multi-coated inhomogeneities. Int. J. Solid Struct. 47, 2893-2904 (2010).

172. P. Barai and G.J. Weng. A micro-continuum model for the creep behavior of complex nanocrystalline materials. Int. J. Engng. Sci. 49, 155-174 (2011).

173. Y.P. Shi, A.K. Soh and G.J. Weng. Anisotropic mechanism on distinct transition modes of tip-activated multipolarization switching in epitaxial $\mathrm{BiFeO}_{3}$ films. J. Appl. Phys. 109, 024102 (2011).

174. P. Barai and G.J. Weng. A theory of plasticity for carbon nanotube reinforced composites. Int. J. Plasticity 27, 539-559 (2011).

175. P. Barai and G.J. Weng. Mechanics of nanocrystalline coating and grain-size dependence of its plastic strength. Mech. Mater. 43, 496-504 (2011).

176. Y. Su, H.T. Chen, J. Li, A.K. Soh and G.J. Weng. Effects of surface tension on the size-dependent ferroelectric characteristics of free-standing BaTiO3 nano-thin films. J. Appl. Phys. 110, 084108 (2011).

177. Y. Pan, G.J. Weng, S.A. Meguid, W.S. Bao, Z.H. Zhu, and A.M.S. Hamouda. Percolation threshold and electrical conductivity of a two-phase composite containing randomly oriented ellipsoidal inclusions. J. Appl. Phys. 110, 123715 (2011).

178. X. Guo, G.J. Weng and A.K. Soh. Ductility enhancement of layered stainless steel with nanograined interface layers. Computational Mater. Sci. 55, 350-355 (2012).

179. W.S. Bao, S.A. Meguid, Z.H. Zhu, Y. Pan and G.J. Weng. A novel approach to predict the electrical conductivity of multifunctional nanocomposites. Mech. Mater. 46, 129-138 (2012).

180. H.H. Pan and G.J. Weng. Investigation of the age-dependent constitutive relations of mortar. ASCE J. Engng. Mech. 138, 297-306 (2012).

181. W.S. Bao, S.A. Meguid, Z.H. Zhu and G.J. Weng. Tunneling resistance and its effect on the electrical conductivity of CNT nanocomposites. J. Appl. Phys. 111, 093726 (2012). 
182. Y. Pan, G.J. Weng, S.A. Meguid, W.S. Bao, Z.H. Zhu, and A.M.S. Hamouda. Interface effects on the viscoelastic characteristics of carbon nanotube polymer matrix composites. Mech. Mater. 58, 1-11 (2013).

183. J. Li and G.J. Weng. A micromechanical approach to the stress-strain relations, strain-rate sensitivity and activation volume of nanocrystalline materials. Int. J. Mech. Mater. Des. 9, 141-152 (2013).

184. N. Liu, Y. Su and G.J. Weng: A phase-field study on the hysteresis behaviors and domain patterns of nanocrystalline ferroelectric polycrystals. J. Appl. Phys. 113. 204106 (2013).

185. W.S. Bao, S.A. Meguid, Z.H. Zhu, Y. Pan and G.J. Weng. Effect of carbon nanotube geometry upon tunneling assisted electrical network in nanocomposites. J. Appl. Phys. 113, 234313 (2013).

186. G.J. Weng. The Prager Medal Lecture: Micromechanics and some aspects of phase fields in ferroelectric crystals. Acta Mech. (in press, 2014). 